BMJ Open Sport \& Exercise Medicine

\title{
Characteristics of transplant athletes competing at national and international transplant games
}

Thomas Hames, Sheila Leddington-Wright, Charles Douglas Thake, Mike Price

\section{ABSTRACT}

Leddington-Wright $\mathrm{S}$, Thake $\mathrm{CD}$, et al. Characteristics of transplant athletes competing at national and international transplant games. BMJ Open Sport \& Exercise Medicine 2022;8:e001248. doi:10.1136/ bmjsem-2021-001248

- Additional supplemental material is published online only. To view, please visit the journal online (http://dx.doi. org/10.1136/bmjsem-2021 001248).

Accepted 17 January 2022
Objective To describe the characteristics of athletes with solid-organ transplants (TxA) attending the British and World Transplant Games.

Methods 220 TxA completed an online survey to explore transplant history, medications, training advice and support and limitations to training.

Results TxA were predominantly caucasian, male, kidney recipients in their mid-forties and approximately 11 years post-transplant. The majority of TxA took some form of medication (immunosuppressants $88 \%$, steroids $47 \%$, antihypertensives $47 \%$, statins $28 \%$, antiplatelets $26 \%$, antibiotics/antivirals/antifungals 20\%). Stem cell recipients were least likely to require medication. Post-transplant complications were experienced by $40 \%$ of TxA, with $53 \%$ of these being rejection. Although over half the participants $(57 \%)$ initially received exercise or training advice posttransplant, only $34 \%$ of these received this from their consultants or immediate medical team. Only $1 \%$ had been specifically directed towards transplant sport. Half of the TxA (53\%) perceived there were limitations preventing them from performing at their potential, $45 \%$ considered they did not recover from training as well as non-TXA while $29 \%$ felt they trained equally to non-Tx's. Only $6 \%$ considered medication impaired training. TxA competed for a range of reasons from social and health benefits to winning medals.

Conclusions TxA compete at the British and World Transplant Games for a diverse range of reasons. Athletes manage a range of medications with a range of exercise and health experiences pre-transplant. TxA face a lack of both general and specific exercise training and recovery guidance. The individuality of each TxA's background should be considered and is likely reflected in their exercise capacity and goals.

\section{Key messages}

What is already known on this topic

- Athletes with solid-organ transplants (TXA) demonstrate reduced physiological responses to exercise.

- Reduced peak oxygen uptake results from chronic reductions in muscle mass and muscle quality prior to surgery.

- Post-transplant, physiological responses may not recover due to immunosuppressant drug interactions.

- Competitors in transplant events are reported to be predominantly male kidney recipients between 42 and 46 years of age, managing comorbidities and concurrent medications. The characteristics and needs of TXA has received little attention.

\section{What this study adds}

- The majority of TxA manage multiple medications, often being specific to their transplant type.

- Many competitors attend the Games for the healthrelated benefits and fitness, competing for enjoyment, with a smaller proportion competing to win.

- Few competitors follow any structured training advice from exercise professionals.

- Each TxA's journey differs with respect to transplant type and exercise experience which is likely reflected in their exercise capacity and goals.

How this study might affect research, practice or policy

- There is a need to understand current TxA training practices and develop appropriate high performance, sport-specific training guidance post-transplant for those recipients wishing to compete.

- Practitioners should be aware that a TxA desire to compete is multifaceted and often beyond that of athletic competition alone. Each competitor has a unique background to consider.
Check for updates

(C) Author(s) (or their employer(s)) 2022. Re-use permitted under CC BY. Published by BMJ.

Health and Life Sciences, Coventry University, Coventry, UK

Correspondence to Dr Mike Price;

mike.price@coventry.ac.uk

\section{INTRODUCTION}

Determining the characteristics of athletic populations enables optimisation of training and performance. ${ }^{1-3}$ For coaches and other members of the support team in daily contact with athletes, knowledge of their specific requirements is essential. ${ }^{4}$ Some athlete groups though (eg, asthma, diabetes, disability) present the support team with an additional challenge of managing medical conditions and medication around daily training and competitions. A group of athletes facing considerable medication challenges are athletes with solid-organ transplants. Transplant recipients also demonstrate reduced physiological responses to exercise, such as peak oxygen uptake $\left(\mathrm{VO}_{2 \text { peak }}\right)$. Posttransplant, reduced $\mathrm{VO}_{2 \text { peak }}$ may be a result of chronotropic incompetence in an otherwise well-functioning allograft, such as for heart recipients or allograft dysfunction. However, 
key contributors to reduced $\mathrm{VO}_{2 \text { peak }}$ are chronic reductions in muscle mass and muscle quality prior to surgery that may not recover post-transplant due to immunosuppressant drug interactions. ${ }^{5}$ Although position stands relating to athletes with asthma ${ }^{6}$ and diabetes ${ }^{7}$ exist, the characteristics and needs of athletes with solid-organ transplants (TxA) has received little attention.

Since the inaugural Transplant Games in 1978 participant numbers have grown from 99 competitors representing five countries to 1500 competitors representing 69 countries at the 2017 World Transplant Games in Malaga. ${ }^{8}$ Despite this increase in participation, there is limited empirical data regarding demographics, physical characteristics and medication regimes of TxA attending the Games. Existing data suggests participants at Transplant Games have predominantly been male kidney recipients with a mean age of $42-46$ years ${ }^{9-13}$ Data from the 1996 US Transplant Games ${ }^{9}$ and 2012 Latin American Transplant Games ${ }^{13}$ reported a high proportion (52\%) of competitors managing one or more comorbid conditions while a small proportion $(7 \%)$ experienced graft rejection within the 12 months prior to competition. Competitors at these events managed concurrent medications with continuous immunosuppressant management evident among nearly all TxA. In addition to medications, TxA differ from other athlete groups as they compete with respect to age across a range of events. As such, typical training guidelines are unlikely able to cater for the wider age range of TxA's. Furthermore, the specific journey of each transplant recipient differs considerably. ${ }^{14}$ To our knowledge, no study examining TxA has concurrently reported the training advice received, perceptions of training and performance limitations alongside generic transplant information which has the potential to support both transplant recipients and practitioners presurgery and postsurgery. The aim of this study was to determine the characteristics of TxA attending the British and World Transplant Games.

\section{METHOD}

\section{Participants}

A survey-based study was completed by 220 English speaking TxA's (male: 139, female: 81). Gatekeeper consent for national and international standard athletes was provided from the World Transplant Games Federation, Transplant Sport UK and national team managers as part of the institutional ethics process. The questionnaire was advertised on the World Transplant Games Federation and Transplant Sport UK websites. The survey was open for $\sim 10$ weeks from 12 June 2017 to 1 September 2017. No reminders to complete the survey were posted. Participants provided individual consent which was built into the questionnaire. Inclusion criterion was successful entry into the 2017 British or World Transplant Games which, in doing so, confirmed the TxA had met the required conditions for competition, that is, having received one or more life supporting allografts (kidney, liver, heart, stem cell, lung, pancreas, intestine), be more than 6 months post-transplant and with a stable allograft and medically fit as signed off by their doctor. ${ }^{8}$

\section{Survey procedure}

A 63-question survey was developed to explore training practices, recovery postexercise, training advice and support undertaken and experienced by TxA and is fully available as online supplemental appendix 1. Questions relating to TxA characteristics (sex, age, height, body mass (enabling body mass index calculation; BMI, mass/ height $\left.{ }^{2} ; \mathrm{kg} / \mathrm{m}^{2}\right)$, nationality and ethnicity), transplant history (initial reason for transplant and age at transplant), medications, complications, source of exercise/ training advice and reasons for attending Tx Games are reported here.

Participants completed the survey on the Bristol Online Survey platform using a web link available through the World Transplant Games Federation web page and consenting national team web pages. Further recruitment occurred through word of mouth at both the British Transplant Games (Glasgow; 27 July 2017-30 July 2017) and the World Transplant Games (Malaga; 24 June 2017-30 June 2017). The survey was piloted using transplant athletes $(n=4)$ to assess clarity and practicality of completion. Feedback from the pilot study indicated the survey allowed participants to reflect on their journey from illness to athlete and what they have been able to achieve through physical training. Furthermore, participants indicated they were happy to answer all questions, taking between 15 and 20 min to complete.

\section{Statistical analysis}

Survey analysis was predominantly descriptive in nature with frequency distributions for the whole group and for males and females, type of transplant, etc as appropriate reported. Normality was determined using the Kolmogorov-Smirnov test prior to independent t-tests and two-way analysis of variance for the comparisons between subgroups for sex, age, height, body mass and BMI.

\section{Patient and public involvement}

Althetes with solid organ transplants were involved in piloting the questionnaireand will be involved in the dissemination plans of this research.

\section{RESULTS}

\section{Participant characteristics}

The overall ratio of male:female TxA was $63: 37 \%$. Within the five largest subgroups based on transplant type liver recipients had fewer males whereas stem cell and lung recipients had more males (table 1 ). With the exception of lung recipients, where males and females were of similar mass $(\mathrm{p}=0.686)$, males were generally heavier than females $(p=0.006)$. BMI was comparable across the five largest sub-groups. Mean age of TxA was similar across the majority of subgroups with similarly large age ranges across groups. Time since transplant was also 
Table 1 Characteristics of competitors attending the British and World Transplant Games $(n=220)$

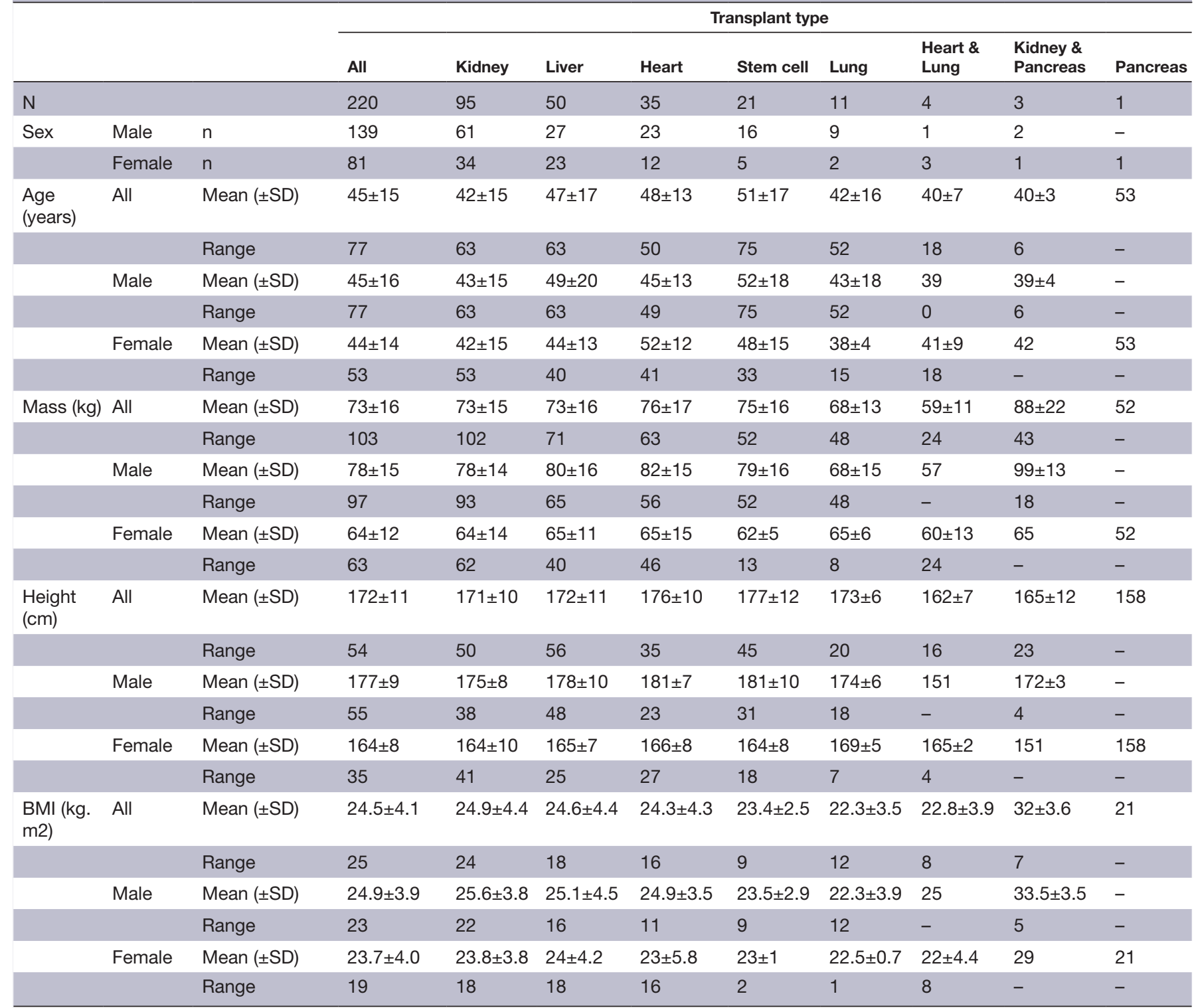

Grouped according to transplant subgroup, as per British Transplant Games and World Transplant Games competitions.

BMI, body mass index.

similar across transplant type. The majority of participants $(57 \%)$ acquired a chronic illness in adulthood resulting in organ transplantation with smaller frequencies for those undergoing transplant as a child (19\%), children reaching adulthood prior to transplant $(16 \%)$ and adults with a sudden onset of illness leading to transplant $(9 \%)$. Athletes were predominantly white caucasian when considered as the whole group, UK and non-UK countries (90, 95, 83\%, respectively). All other ethnic groups represented less than $5 \%$ of both UK and non-UK participants.

\section{Medications and complications}

TxA took an average of $5 \pm 3$ medications each week and were advised to take daily vitamins or minerals (see online supplemental information). The greatest number of weekly medications was reported by lung recipients
$(8 \pm 4)$, whereas stem cell recipients managed the least $(2 \pm 2), 43 \%(n=9)$ of whom took no medication. One or more immunosuppressants were manged by $88 \%$ of TxA, of which, the most frequent users were heart recipients $(100 \%)$, while stem cell recipients were least frequent users $(10 \%)$. Steroid medication was managed by $47 \%$ of TxA of which lung recipients managed the most (82\%) and liver recipients managed the least (26\%). Antihypertensive management $(47 \%)$ was apparent in all $\mathrm{Tx}$ subgroups, heart recipients managed the most $(69 \%)$ whereas stem cell recipients managed the least $(10 \%)$. Statin and antiplatelet medications were managed by $28 \%$ and $26 \%$ of TxA, respectively, predominantly by heart recipients $(80 \%, 37 \%$, respectively) and least frequently by stem cell recipients $(0 \%, 5 \%$, respectively), with no lung recipients taking antiplatelets. Antibiotics/antiviral/ 
Table 2 Prevalence of complications within competitive transplant recipients and the five most common subgroups since transplant

\begin{tabular}{|c|c|c|c|c|c|c|}
\hline & Total & Kidney & Liver & Heart & Stem cell & Lung \\
\hline $\begin{array}{l}\text { No of complications } \\
\text { (Percentage within transplant group) }\end{array}$ & $\begin{array}{l}88 / 220 \\
40\end{array}$ & $\begin{array}{l}37 / 95 \\
39\end{array}$ & $\begin{array}{l}23 / 50 \\
46\end{array}$ & $\begin{array}{l}12 / 35 \\
34\end{array}$ & $\begin{array}{l}8 / 21 \\
38\end{array}$ & $\begin{array}{l}7 / 11 \\
64\end{array}$ \\
\hline Rejection, minor rejection (\%) & 53 & 51 & 65 & 67 & 13 & 43 \\
\hline Cancer/lymphoproliferative disease (\%) & 6 & 3 & 4 & - & 13 & 29 \\
\hline Other organ damage (\%) & 10 & 16 & 9 & - & 13 & 14 \\
\hline Anaemia (\%) & 2 & 3 & - & 8 & - & - \\
\hline Infection (\%) & 10 & 11 & 9 & 17 & - & 14 \\
\hline Graft versus host disease (\%) & 5 & - & - & - & 50 & - \\
\hline Other (\%) & 13 & 16 & 13 & 8 & 13 & - \\
\hline
\end{tabular}

antifungal medication use was reported in $20 \%$ of TxA and was observed across all Tx subgroups (eg, lung recipients $90 \%$, kidney recipients $9 \%$ ). Complications post-Tx were experienced by $40 \%(n=88)$ of TxA (table 2$)$. Organ rejection whether minor or complete accounted for $53 \%$ of all complications and, while prevalent within all $\mathrm{Tx}$ subgroups, rejection complications were greatest among heart recipients accounting for $67 \%$ of all complications. Infection and associated organ damage were both experienced by $10 \%$ of TxA experiencing complications. Graft versus host disease was experienced among $50 \%$ of stem cell recipients.

\section{Exercise advice}

Post-transplant $57 \%$ of TxA received training guidance or advice from sources such as; consultant/medical support team (34\%), supporting therapists $(8 \%)$, coach $(4 \%)$, family and friends $(4 \%)$, another recipient $(2 \%)$ or other $(5 \%)$. When given, training advice consisted of; encouraging physical activity and given some form of criteria $(25 \%)$, directed towards therapy classes $(23 \%)$, told to take it gentle and slow but nonspecific (8\%). A small proportion of TxA were unclear on what had been advised $(3 \%)$, whereas only $1 \%$ were encouraged to explore the Tx Games.

\section{Performance limitations}

Over half the participants $(53 \%)$ perceived that there was an existing limitation preventing them from performing at their true potential. Of these, current injury or illness $(23 \%)$, lack of fitness/strength $(18 \%)$, fear of overdoing it and lack of motivation (13\%), finance and time limitations $(10 \%)$, medication $(8 \%)$, a lack of understanding from coaches and supporting networks (8\%) were reported. However, $43 \%$ of participants $(n=96)$ were actively trying to improve on these factors by increasing levels of activity (37\%), seeking further advice from Sports Therapists and Physiotherapists (13\%) and factoring in more time to train $(6 \%)$. Some TxA though believed nothing would change in relation to their current limitations $(17 \%)$.

\section{Perceived training intensity}

When asked to compare their ability to train to that of an event matched non-TxA 29\% felt they trained equally, $21 \%$ felt they could train the same for $75 \%$ of the time, $19 \%$ could train the same $50 \%$ of the time, whereas $16 \%$ reduced the intensity of their training session from the start of the session. The greatest training adjustments were reported by heart recipients with $37 \%$ modifying their sessions from the start and $23 \%$ adjusting up to $50 \%$ of a training session. When considering the recovery between sessions on back-to-back training day's $55 \%$ of all TxA believed they recovered equally to an event matched non-TxA whereas over half (52\%) of heart recipients believed their recovery was impaired. For the whole group, $14 \%$ believed chronic fatigue impaired recovery, being greatest for the heart-recipients $(26 \%)$ and least for the lung recipients $(9 \%)$. Although only $6 \%$ of the whole group believed medication impeded their recovery, this was greatest among heart recipients (14\%) with no stem cell or lung recipients reporting this.

\section{Participation reasons}

When exploring reasons why TxA participated at various Transplant Games $65 \%$ wanted to improve their fitness, $62 \%$ attended to be part of the $\mathrm{Tx}$ community, $61 \%$ competed for fun, $60 \%$ participated to encourage a healthier lifestyle, $31 \%$ aimed to win international events, $27 \%$ aimed to win national events, $20 \%$ attended to compete at events they competed in prior to transplant, $16 \%$ to compete at new events and $12 \%$ attended to break records.

\section{DISCUSSION}

To our knowledge, this is the first study to report the characteristics of TxA's attending the British and World Transplant Games. The main findings were that TxA were generally caucasian, male, kidney recipients in their midforties approximately 11 years post-transplant. Stem cell recipients were potentially the only TxA not commonly requiring medication, otherwise, all TxA took some form of medication. A high proportion of all TxA experienced complications post-transplant. Just over half the 
participants had received guidance or advice on exercise or training post-transplant, with only $1 \%$ being directed towards the Transplant Games or Transplant Sport. A high proportion of TxA perceived there were limitations preventing them from performing at their potential, yet $29 \%$ felt they trained equally to non-TxA's. The majority participated at the Transplant Games to improve their fitness and be part of the transplant community. Only a small proportion attended to win titles and break records.

\section{Participant characteristics}

The age, male:female ratio and BMI of the current study are similar to previous reports of TxA. ${ }^{910}$ Competitors are generally older than expected for non-transplant athletes at international competitions (ie, 23-28 years) ${ }^{1516}$ as a large proportion of the TxA received their transplant during adulthood subsequent to chronic illness as a child. Furthermore, transplant sport involves competing in age categories up to $70+$ years, ${ }^{8}$ thus, many older competitors exist than would be expected for non-transplant sport.

\section{Medications and complications}

While medications play a vital role in maintaining a healthy lifestyle and transplant homeostasis, they also carry associated risks. For example, immunosuppressants (eg, tacrolimus or ciclosporin) can increase the risk of infections, for which approximately $20 \%$ of TxA in the current study were prescribed antibiotics. Long-term side effects of immunosuppressants include kidney disease, high blood pressure and cholesterol, diabetes, osteoporosis and the risk of certain cancers, ${ }^{17}$ which may require further medical intervention. Steroids (eg, prednisone) also carry potential side effects including hypertension, hypercholesterolaemia, high blood glucose, weight gain and anxiety. ${ }^{12}$ In comparison to other transplant types, stem cell recipients took the fewest medications. Practitioners working with TxA should be aware of the specific type of transplant and the likely medications taken as well as their effects on exercise-as has been noted for commonly prescribed medications. ${ }^{18}$ However, the specific effects of typical transplant related medications on exercise responses are generally unreported as the focus of many such medications are, understandably, to offset allograft rejection. Physical activity and exercise though can play a pivotal role in negating common side effects improving health-related quality of life compared with sedentary transplant recipients ${ }^{19} 20$ and comparable to the general population. ${ }^{21}$ Indeed, BMI of the current participants was below values associated with graft dysfunction and poor survival (ie, $<25 \mathrm{~kg} / \mathrm{m}^{2}, 22<30$ $\left.\mathrm{kg} / \mathrm{m}^{2}{ }^{23}\right)$. Complications though were experienced by the TxA being predominantly minor or major allograft rejection, which remains the greatest barrier to successful transplantation. ${ }^{24}$ Previous research of TxA at the 1996 US Transplant Games reported a greater prevalence of TxA competing with one or more underlying comorbid conditions than this study ( $79 \%$ vs $40 \%$, respectively). ${ }^{9}$ Thus, managing complications or comorbid conditions
post-Tx is not regarded as uncommon, for which exercise practitioners should be aware.

\section{Exercise advice}

Although it was encouraging that $57 \%$ of TxA were given exercise and training advice post-transplant this generally referred to low intensity exercise for health and 'not to overdo it'. Plausible reasons are most likely related to post-transplant immunosuppressant doses being at their highest during the first 3 months as the risk of acute rejection and allograft loss is also highest. ${ }^{25}$ Subsequent tapering of doses means organ recipients are then at an increased risk of community-acquired infection. ${ }^{26}$ The acute effects of exercise on immune function depression observed in non-transplant populations ${ }^{27}$ could further potentially contribute to increased infection risk. Most of the scientific evidence in support of regular exercise for transplant recipients was published in the last ten years, thus, initial advice given to the current study's participants ( $\sim 1$ years prior) could justifiably have been conservative. The lack of published evidenced based practice for TxA within physiotherapy and sports therapy ${ }^{28}$ also appears to exist for exercise and training advice.

\section{Performance limitations}

Over half of the TxA (53\%) perceived there to be an existing limitation to their performance, the most frequent responses relating to injury or illness and lack of fitness. Although this study did not assess the specific nature of injuries, it is important to recognise that in non-transplant recipient runners, injuries such as stress fractures accounts for $\sim 69 \%$ of all overload injuries. ${ }^{29}$ Chronic immunosuppressant and glucocorticoid use by transplant recipients increases the potential for osteoporosis and fractures whether involved in sport or not. ${ }^{3031}$ For example, research assessing injury 8 years post-transplant reported fracture incidence as high as $46 \%$ in liver transplant recipients. ${ }^{32}$ Predisposing risk factors for injury include age, BMI, health, physical fitness, skill level, ${ }^{33}$ excessive loading, insufficient recovery and underpreparedness. ${ }^{34}$ A large number of TxA could therefore be at an accentuated risk of injury.

Although less than one-third of TxA considered they could train at a similar intensity as non-transplant recipient athletes, over half felt they recovered as well. The latter maybe a factor of reduced training intensity undertaken or a result of those competitors who were able to train at greater intensity also being those reporting good recovery. Interestingly, over half of the heart-recipients reported recovery was impaired with the majority of athletes reporting recovery being impeded by chronic fatigue also being heart-recipients. It is therefore possible that the heart-recipients may be more physiologically limited dependent on, among other factors, the number of medications taken and the magnitude of sympathetic nervous system re-innervation potentially affecting cardiovascular responses. Transplant athletes as a group, however, may not fully understand their own limitations. 
Future studies should assess the physiological responses to exercise and recovery in TxA to enable more specific exercise and training advice to be provided.

\section{Participation reasons}

Although the physiological benefits of exercise for organ recipients have been reported, ${ }^{19-21}$ many other reasons exist for exercise participation including; psychological, environmental, behavioural, social and cultural factors. ${ }^{35}$ Within the current population four main reasons for competing were reported, two of which were indeed related to physiological aspects; to improve fitness and encourage a healthier lifestyle. The third reason reported was to compete for fun. For a group of nontransplant participants who were younger (18-25 years) but similar to the current population in terms of ethnicity (80\% white) and BMI, men exercised for enjoyment more so than women who exercised for weight related reasons,${ }^{36}$ a finding that has recently been observed for TxA. ${ }^{37}$ As the current population were Transplant Games competitors, it could be argued that both male and female participants may be more competitively motivated. However, much smaller numbers of competitors aimed to win national or international events with even fewer competing to break records, thus highlighting a predominantly enjoyment-based driver. However, the fourth reason for participation discriminates TxA from conventional athletic competitors by participating to be part of the transplant community. At transplant games events TxA are able to meet peers who have overcome similar adversity and who have received the 'gift of life, ${ }^{, 38}$ which is unique to this population. Social support from friends and family, previously identified as strong associates for physical activity, ${ }^{35}$ are also likely to drive TxA who have experienced significant health issues. ${ }^{14} 38$ and should be studied further in this population.

\section{Limitations}

While over 200 TxA responded to the survey this was limited to English speakers from 20 nationalities, thus, the characteristics of all nations competing at the World Transplant Games are not represented. The inclusion of TxA's from a wider selection of nations, could consolidate exercise practices and improve training recommendations. Although the predominance of white males within our TxA population is similar to previous studies ${ }^{9}{ }^{39}$ the proportion of black, Asian and minority ethnic groups receiving organs in the UK was not reflected in our sample. Although we did not set out to assess ethnicity per se it is plausible that these recipients face additional health and cultural related challenges, for which participation at transplant events holds a lesser priority. ${ }^{40}{ }^{41}$ Each TxA's journey and training experience should thus be considered. Finally, the survey was only open to TxA over 18 years of age, yet a large part of the Transplant Games' philosophy is to inspire those under 18 to increase activity and compete. An understanding of young TxA is essential to optimise their transplant journey.

\section{CONCLUSION}

This study details the characteristics of TxA attending the British and World Transplant Games. With the exception of stem cell recipients, the majority of TxA manage multiple medications, often being specific to their transplant type. Many TxA's attend the Games for the health-related benefits and fitness. Although many TxA compete for enjoyment a smaller proportion compete to win. More specific guidance post-transplant needs to be developed regarding physical activity, exercise, and reduction of injury risk. Each TxA's journey differs with respect to transplant type and exercise experience which is likely reflected in their exercise capacity and goals.

Contributors TH developed the questionnaire, collected and analysed data and wrote the initial draft of the manuscript. SL-W contributed to study concept, design of the questionnaire and reviewed the manuscript. CDT contributed to study concept, design of the questionnaire and reviewed the manuscript. MP contributed to study concept, design of the questionnaire, data analysis and edited the manuscript. MP led the manuscript revision with all other authors reviewing edits TH and MP are the guarantors.

Funding The authors have not declared a specific grant for this research from any funding agency in the public, commercial or not-for-profit sectors.

Competing interests None declared.

Patient consent for publication Consent obtained directly from patient(s)

Ethics approval This study involves human participants and was approved by Coventry University Ethics approval (approved 30 May 2017; Application P52535). Participants gave informed consent to participate in the study before taking part.

Provenance and peer review Not commissioned; externally peer reviewed.

Data availability statement All data relevant to the study are included in the article or uploaded as online supplemental information. Not applicable.

Open access This is an open access article distributed in accordance with the Creative Commons Attribution 4.0 Unported (CC BY 4.0) license, which permits others to copy, redistribute, remix, transform and build upon this work for any purpose, provided the original work is properly cited, a link to the licence is given, and indication of whether changes were made. See: https://creativecommons.org/ licenses/by/4.0/.

ORCID iD

Mike Price http://orcid.org/0000-0003-4274-0624

\section{REFERENCES}

1 James LP, Haff GG, Kelly VG, et al. Towards a determination of the physiological characteristics distinguishing successful mixed martial arts athletes: a systematic review of combat sport literature. Sports Med 2016;46:1525-51.

2 Hellard P, Avalos-Fernandes M, Lefort G, et al. Elite swimmers' training patterns in the 25 weeks prior to their season's best performances: insights into Periodization from a 20 -Years cohort. Front Physiol 2019;10:363.

3 Pollock S, Gaoua N, Johnston MJ, et al. Training regimes and recovery monitoring practices of elite British swimmers. J Sports Sci Med 2019;18:577-85.

4 Johnson SR, Wojnar PJ, Price WJ. A Coach's Responsibility: Learning How to Prepare Athletes for Peak Performance. Sport J 2011;22:1-14.

5 Williams TJ, McKenna MJ. Exercise limitation following transplantation. Compr Physiol 2012;2:1937-79.

6 Miller MG, Weiler JM, Baker R, et al. National athletic trainers' association position statement: management of asthma in athletes. $J$ Athl Train 2005;40:224-45.

7 Jimenez CC, Corcoran MH, Crawley JT, et al. National athletic trainers' association position statement: management of the athlete with type 1 diabetes mellitus. J Athl Train 2007;42:536-45.

8 World Transplant Games Federation. Rules for the sports of the 2017 world transplant games. In: Sports Rules - World Transplant Games Federation, 2016: 1-14. 
9 Painter PL, Luetkemeier MJ, Moore GE, et al. Health-Related fitness and quality of life in organ transplant recipients. Transplantation 1997;64:1795-800.

10 Johnson U, Hinic H, Billstrom A. Transplant recipients' experience of participation at the world transplant games in Gothenburg 2011: a study of psychological well-being. Open Transplant J 2013.

11 Deliva RD, Patterson C, So S, et al. The world transplant games: an incentive to improve physical fitness and habitual activity in pediatric solid organ transplant recipients. Pediatr Transplant 2014;18:889-95.

12 Patel S. Organ transplant medicine. S Afr Pharm J 2015;2:22-7.

13 Atamañuk AN, Ortiz Fragola JP, Casonu M, et al. Physical activity among organ recipients: data collected from the Latin American transplant games. Transplant Proc 2017;49:354-7.

14 Leddington-Wright S, Price MJ. The transplant athlete: an emerging sporting population. Br J Sports Med 2018 http://blogs.bmj.com/ bjsm/2018/03/07/the-transplant-athlete-an-emerging-sportingpopulation/

15 Hollings SC, Hume PA, Hopkins WG. Relative-age effect on competition outcomes at the world youth and world junior athletics Championships. Eur J Sport Sci 2014;14 Suppl 1:S456-61.

16 Allen SV, Hopkins WG. Age of peak competitive performance of elite athletes: a systematic review. Sports Med 2015;45:1431-41.

17 Patel JK, Kobashigawa JA. Heart transplantation. Circulation 2011;124.

18 Bouchard MP. Medications and exercise. ACSMs Health Fit J 2012;16:34-6.

19 Painter P, Krasnoff J, Paul SM, et al. Physical activity and healthrelated quality of life in liver transplant recipients. Liver Transpl 2001;7:213-9.

20 Cicognani E, Mazzoni D, Totti V, et al. Health-Related quality of life after solid organ transplantation: the role of sport activity. Psychol Health Med 2015;20:997-1004

21 Mazzoni D, Cicognani E, Mosconi G, et al. Sport activity and healthrelated quality of life after kidney transplantation. Transplant Proc 2014;46:2231-4.

22 Kostakis ID, Kassimatis T, Bianchi V, et al. Uk renal transplant outcomes in low and high BMI recipients: the need for a national policy. J Nephrol 2020;33:371-81.

23 Owen RV, Thompson ER, Tingle SJ, et al. Too fat for transplant? the impact of recipient BMI on pancreas transplant outcomes. Transplantation 2021;105:905-15.

24 Knight SR, Alasadi A, Clancy M. The immunology of solid organ transplantation. Anaesthesia \& Intensive Care Medicine 2018;19:579-82.

25 Barlow AD, Saeb-Parsy K, Watson CJE. An analysis of the survival outcomes of simultaneous pancreas and kidney transplantation compared to live donor kidney transplantation in patients with type 1 diabetes: a UK transplant registry study. Transpl Int 2017;30:884-92.
26 Fishman JA. Infection in solid-organ transplant recipients. N Engl J Med 2007;357:2601-14.

27 Gleeson M, Walsh NP, British Association of Sport and Exercise Sciences. The bases expert statement on exercise, immunity, and infection. J Sports Sci 2012;30:4-15.

28 Leddington Wright S, Bloxham A, Hames T, et al. Therapeutic perceptions in management of transplant athletes at transplant games. Phys Ther Sport 2019;39:114-9.

29 Miller TL, Best TM. Taking a holistic approach to managing difficult stress fractures. J Orthop Surg Res 2016;11:98.

30 Braga Júnior JWR, Neves RMS, Pinheiro MM, et al. Prevalence of low trauma fractures in long-term kidney transplant patients with preserved renal function. Braz J Med Biol Res 2006;39:137-47.

31 Edwards BJ, Desai A, Tsai J, et al. Elevated incidence of fractures in solid-organ transplant recipients on glucocorticoid-sparing immunosuppressive regimens. J Osteoporos 2011;2011:1-8.

32 Guichelaar MMJ, Schmoll J, Malinchoc M, et al. Fractures and avascular necrosis before and after orthotopic liver transplantation: long-term follow-up and predictive factors. Hepatology 2007;46:1198-207.

33 Bahr R, Holme I. Risk factors for sports injuries--a methodological approach. Br J Sports Med 2003;37:384-92.

34 Aicale R, Tarantino D, Maffulli N. Overuse injuries in sport: a comprehensive overview. J Orthop Surg Res 2018;13:309.

35 Trost SG, Owen N, Bauman AE, et al. Correlates of adults participation in physical activity: review and update. Med Sci Sports Exerc 2002;34:1996-2001.

36 Craft BB, Carroll HA, Lustyk MKB. Gender differences in exercise habits and quality of life reports: assessing the moderating effects of reasons for exercise. Int J Lib Arts Soc Sci 2014;2:65-76.

37 Jooste J, Rogerson D, Hogg M. Transplant recipients' motivational orientation towards sport participation and physical activity enjoyment at the 2019 World Transplant Games in NewcastleGateshead UK. J Hum Sport Exerc 2020;15:S481-94.

38 Slapak M. Sport and transplantation. Ann Transplant 2005;10:60-7.

39 McBean JM. An injury surveillance of patients utilising the Durban University of technology (DUT) chiropractic treatment facilities at the 2013 world transplant games, MSC thesis. Durban University of Technology, 2015. https://openscholar.dut.ac.za/bitstream/10321/ 1424/1/MCBEAN_2015.pdf

40 Randhawa G, Neuberger J. Role of religion in organ DonationDevelopment of the United Kingdom faith and organ donation action plan. Transplant Proc 2016;48:689-94.

41 Pisavadia B, Arshad A, Chappelow I, et al. Ethnicity matching and outcomes after kidney transplantation in the United Kingdom. PLoS One 2018;13:e0195038. 